Original Research

\title{
Planning for Simultaneous Regional/Urban and Tourism Development with Case Studies
}

Abdol Aziz Shahraki *

Professor Engineering Dr., Managing Director, and senior researcher at the Knowledge and Implementation Consulting Engineering Co - Iran; E-Mail: aa.shahraki@yahoo.com

* Correspondence: Abdol Aziz Shahraki; E-Mail: aa.shahraki@yahoo.com

Academic Editor: Zed Rengel

Adv Environ Eng Res

2021, volume 2 , issue 4

doi:10.21926/aeer.2104035
Received: September 18, 2021

Accepted: December 07, 2021

Published: December 17, 2021

\begin{abstract}
This research suggests optimal planning and designing techniques for tourism complexes in urban master planning. Firstly, it explains the importance of the tourism industry through the theories of scholars and experts. It also emphasizes the connection between the development of urban economies and the tourism industry. This helps integrate the tourism industry and comprehensive regional/urban planning. It starts with planning and designing the tourism complexes in the early stages of the municipality's master plan. This research paper suggests urban land-use policies and location techniques. This paper brings out landuse policies and centralized and symmetric urban design models for regional/urban sustainable development. It charts the following steps to meet the goal: determining a location for a tourism complex, setting a spatial table of required construction, preparing a land-use map, preparing a map album, developing investment and construction contracts. This paper assists civil engineers, urban and regional planners, tourism industry bodies, and students to develop rationally and optimally.
\end{abstract}

\section{Keywords}

Tourism planning; destination; tourism complex; regional development; master planning; a centralized design model

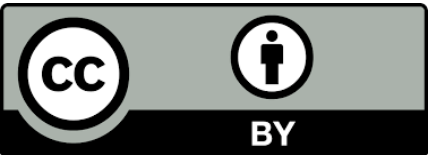

(C) 2021 by the author. This is an open access article distributed under the conditions of the Creative Commons by Attribution License, which permits unrestricted use, distribution, and reproduction in any medium or format, provided the original work is correctly cited. 


\section{Introduction}

Tourism is one of the largest industries, with its origin in ancient Romans and Greece. It has long been appreciated for its economic benefits [1]. Prehistoric people traveled to get food, avoid danger, and find a home. Since the formation and expansion of cities and civilizations, one experiences tourism through economic and social relationships [2].

Some scholars believe that tourism emerged in modern social arrangements in $17^{\text {th }}$ century Western Europe. They specified the connections between tourism, travel literature, and the commodification of culture [3].

Post-world war era tourism is one of the most dynamic and developing economic sectors of the global economy. It takes the fourth place among the world industries [4, 5], and the industry is still growing. Many regions strive to improve the tourism industry to develop economies and the quality of life [6]. The World Tourism Organization (WTO) appealed to governments and people to develop indigenous and international tourism [7].

Tourism had rapid progress in several countries before the COVID-19 pandemic. A total of 266 million jobs (8.9\% of employment) involved travel and tourism in 2013, 1 out of 11 of all jobs [8, 9].

The COVID-19 pandemic negatively influenced the tourism industry, and efforts should include designing and constructing tourist complexes to continue its development $[10,11]$.

Tourism is a multifaceted industry and includes several sectors like nature, environment, economy, society, culture, landscape, cities, and villages. It even involves the physical environment, communication methods, regional and urban infrastructures, economic activities, experiences, and relationships between people and investment styles. A tourism destination with adequate natural resources attracts more visitors [12].

Many scholars discussed the meaning of sustainable tourism, as we see in samples [13-16]. Sustainable tourism happens only in sustainable societies. Therefore, sustainable tourism is a part of sustainable urban and regional development. Sustainable tourism, including regional/urban master plan, responsibility for nature, culture, and the social environment, is a tourism issue. It is our responsibility to adapt the tour according to its local sustainability. There are several types of tourism. These types of tourism and the motivations of tourists are dynamic. Patterns and systems of tourism vary as time passes. The changes arise from various cultures, environments, climates, and ecosystems of regions [17].

Every destination, based on its characteristics, plans a type of tourism. Activities with nature and culture get a strong position in tourism. People are also willing to try other types of tourism like excitement, adventure, personal challenge, sport. Another notable tendency of the tourism industry is the collaboration of the native people with tourists. This type of tourism enhances the quality of indigenous inhabitants' life [18].

Every region/country considers the tourism trends that suit its characteristics. The paradigm of the tourism industry is transforming from traditional to creative tourism. Traditional tourism promotes many who will enjoy their free time in several places. However, not all tourists prefer traditional tourism, but many would participate in local cultures and creative activities. They 
promote the merits of these destinations and want to provide the experience of regional/local lifestyles. The latter trend is known as creative tourism. Scholars believe that the mass tourists will advance to creative tourism [19]. Changing demographics and advances in technology increase new tourism trends.

With changing travel patterns, the quality of transportation at tourist destinations is increasingly important. A tourist expects that the selected destination will provide facilities for physical accessibility, information, activity, service offerings, and attitudes. Thus, providing qualified services is crucial for developing functional and high-quality travel destinations.

This study introduces and analyzes the planning and designing techniques of tourism complexes according to tourist needs and local characteristics.

This research hypothesizes tourism planning development requirements to create a regional/urban master plan that includes the progress of tourism industries and regional development simultaneously. Thus, the tourism industry is a part of the municipal master plan more than before.

The research methods help achieve the goal and prove the hypothesis. The methods examine the connection between the development of the tourism industry, strategic urban planning principles, construction of new tourist complexes. It also includes climatic and green architectural design procedures, a centralized design model, optimal use of urban lands, and economic progress.

This research aims to provide a step-by-step design model for tourism complexes that helps develop tourism and region simultaneously.

This article has five parts: Introduction, Theoretical studies, Case studies, Discussions, and Conclusions.

\section{Theoretical Studies}

\subsection{Contents of This Section}

We examine the ideas of scholars about strategic tourism planning, the location of tourist complexes, architectural and landscape design methods according to the characteristics of every region. This section provides a comprehensive action guide for a knowledge base and optimal design of tourism complexes.

\subsection{Strategic Tourism Planning}

The goals of the tourism industry must involve the characteristics and potential of every country and destination [20,21]. According to scholars and workshop experiences, some common strategies can be recommended as general policies for all regions. Firstly, after the COVID-19, all tourist complexes must have preventive, treatment, and care facilities according to the latest World Health Organization protocols. Tourism strategic development through knowledge-based and proficiency plans is necessary. The development of tourism requires long-term international cooperation. This collaboration will include global, regional, national, and local tourism organizations. Other rational policies include increasing public participation and entrepreneurs' competition in tourism development. Building tourism complexes is a necessary strategic plan to improve the existing tourism resources and infrastructures. Tourist-oriented product 
development, handicrafts marketing, and native production is strategic policy. Upgrading the qualities of all tourism services shall also be a central policy.

The urban master plan helps develop the city with transparency and public involvement [22]. Land-use policies assist in preparing an urban strategic development plan for all citizens. A strategy analyzes all socioeconomic factors and their role in the city. Tourism planning shall include the tourism industry requirements from the beginning of the regional/urban planning process. It is necessary to have representatives from the tourism industry in the urban planning and design team from its commencement. There is a connection between the master plan, the protection of the environment, ancient heritages, the improvements of urban and regional infrastructures, and tourism development. The successful planning of a destination addresses the following three questions:

1. Where are we?

2. Where do we go?

3. How do we get there?

We provide a land-use table that illustrates the land area allocated to every user category. The land-use table helps design a map. This map also acts as a basis for the anticipated spaces and provides a physical layout of the tourism complex.

Based on international experiences, the United Nations Habitat suggests the percentage of urban land required for different uses. Table 1 shows the required land percentages according to the UN recommendations and workshop experiences. Table 1 shows the land-use policy abstracted from a workshop in Chabahar.

Table 1 Land-use policy for different users in a tourism complex.

\begin{tabular}{ll}
\hline Category of use & Percent \\
\hline Camping & $5 \%$ \\
Residential, including hotel, villa etc. & $20 \%$ \\
Total economic and commercial activities and sales of handicrafts & $10 \%$ \\
Tourism and hospitality & $10 \%$ \\
Administration and management of the complex & $2 \%$ \\
Educational & $2 \%$ \\
Health and Medical & $6 \%$ \\
Sports such as golf, soccer, volleyball, tennis, etc. & $10 \%$ \\
A network of streets and squares & $25 \%$ \\
Greenspace & $7 \%$ \\
Telecommunication facilities and urban equipment & $3 \%$ \\
Total land of tourism complex & $100 \%$ \\
\hline
\end{tabular}

The table shows the category of use in the left column. The right-hand column represents the percentage of land allocated to each category of use. The design methods of the tourism complex are according to the economic, climatic, and cultural needs of the region. The development of the tourism industry in the master plan is the most recognized and experienced method to improve the tourism industry [23-25]. In the urban planning process, it is necessary to coordinate between different interests, the tourism industry, and strategic policies. The tourism industry's early phases 
of the regional/urban planning process help urban planning with a document of its required areas of land. The master plan reports the general interests, natural and cultural values, existing and planned buildings, road and railway projects, etc. The POM (Problem-Oriented Method) is the best way to plan and design tourism complexes for urban master planning $[26,27]$. Therefore, it is necessary to recognize problems.

The spatial development of the tourism complex is crucial for urban planning and management. We can analyze its location for the spatial and physical development of a tourism complex. We shall study the past, present, and future situations of a tourism complex by the problem-oriented method. The significant factors associated with the sustainable development of the tourism complex are the participation of local social groups, conservation of natural resources, especially water, soil, and plants. It also includes educating citizens to utilize the full potential of the tourism complex. The developing tourism complex creates numerous employment opportunities. It is important to define and introduce necessary projects in the tourism complex. It requires water infrastructure projects, transportation, and other urban infrastructure networks. The tourism complex needs hotels and museums, crafts, art galleries, and health centers' projects, especially with the COVID-19 pandemic experience.

A tourism complex requires green spaces, urban beautification projects, e-commerce sites and stores, and sports places. Projects involving land-use policies shall be introduced in every tourism complex for its physical development.

\subsection{The Location of the Tourism Complexes}

The place is significant in providing goods and services for tourists. The Location theory is an idea for economic geography, regional science, and spatial economics. It addresses questions regarding the aspects of economic activities. Scholars like Richards believed that locating theory assumes that firms choose locations to maximize profits [28]. Van Thanon created the location theory for the agricultural field in 1826. As Marchionatti declared, in 1882 and 1885, Lenhard developed this location theory concerning the industry. Alfred Weber developed its scientific framework in the industry in 1909 [29]. Crystaller and Loch expanded it into central place theories. The location theories aim to minimize production costs. It also considers optimistic attitudes in this industrial age. At the end of the 1960s, a systematic effort integrated the previous theories. The planners wanted to locate manufacturers in places with maximum profits. There are four location theories: Cost minimization, market analysis, maximization, and maximizing revenues. There are groups of location theories and locating models. A locating model is one of the following:

Firstly, the minimum distance model minimizes transportation costs and total production costs.

Secondly, the maximum density model determines the location of services near the population centers. This model includes the desired customer density in each radius.

Thirdly, the minimum power distance model minimizes costs through customer travel to the nearest service centers.

The fourth is the model of maximum coverage maximizing the number of tourists.

All four models are simple mathematical prototypes. Locating indicators and criteria vary with the purpose of the tourism complex [30-32]. A practical procedure to improve strategic planning 
for tourism development is done through workshop experiences. As Shahraki recommended, knowledge-based planning and design will be central[33].

Plans will prevent the spread of slums, the inefficiency of the destination, and the degradation of the environment and natural resources. An experienced and accepted theoretical principle implies urban development will be proportionate to the potential local natural resources. It will focus on accessible water from various sources [33]. We need to understand how many city people can live with the existing resource of water. Another theory focusing on the location recommends the problem-oriented method in urban planning, design, and development. The inefficient planning of the past decades will be addressed with tourism complex buildings. Thus, a problem-oriented strategy helps the strategic social, economic, and physical development of cities. It leads the recommended projects by solving the problems [27, 34].

Regional conditions are considered while locating a tourism complex as well.

Tourists avoid traveling to unsafe, dangerous, and conflict-ridden areas. They also evade harsh environments and risks of natural disasters. The tourism industry requires natural and cultural improvements and adaptation. It requires a coordinated environmental responsibility to achieve sustainable tourism. Environmentally friendly regional and urban planning is the best instrument to decide a location for a tourism complex [35]. We can achieve optimal results in planning by involving and including all relevant actors. The tourism complex is crucial for creating a tourist destination. The physical environment, attractions, accommodation, services, and behavior determine the visitors' experience. We develop quality assurance and eco-labeling and use competitive tools to decide a suitable place for a tourism complex. The ability to imagine these subjects significantly affects the tourism development of a city, a village, or an area by planning and building their tourism complexes. Another condition for selecting lands for a tourism complex is a standard physical environment.

There are connections among the physical environment, the determined lands, the natural environment, water resources, and tourism development situations. The tourism complexes, beautiful squares, streets, sidewalks, and urban infrastructures influence tourism positively. These individual buildings in tourism complexes and details like paving, plantations, furnishings, lighting, and signs create the entire tourism complex. In the mountain village or coastal society, the urban environment and the maintained landscape influence tourist experiences. Improper road construction or a newly constructed environment gives a negative impression. We need to maintain the quality of the natural environment in complexes.

Transport infrastructures like roads, railways, ports, airports, and telecommunications are fundamental. Improvements and investments in transportation increase travel opportunities and visit the destination. In the regional/urban master plan, the communications and connections of the tourism complex with its surrounding environment are successful in this tourism industry.

The location for the tourism complex will be rich in natural resources. Flora, fauna, rich nature, and landscape help increase tourist numbers. The cultural heritage in music, dance, theater, village games, and national holidays are factors that improve the complex. The infrastructure of a tourism complex and the host region will be accessible. Collaboration between public and individual actors is crucial in securing tourist areas and highlighting their development possibilities.

In theoretical studies, the variables that influence the location of tourism complexes are site location and geography, the regional climate, local hydrological features, geology, topology, and 
its natural environment. These factors also include demographic characteristics of the city, local economic capabilities, obstacles to site development, spatial and physical site structures, and urban infrastructures.

Figure 1 illustrates variables affecting the location of the tourism complex.

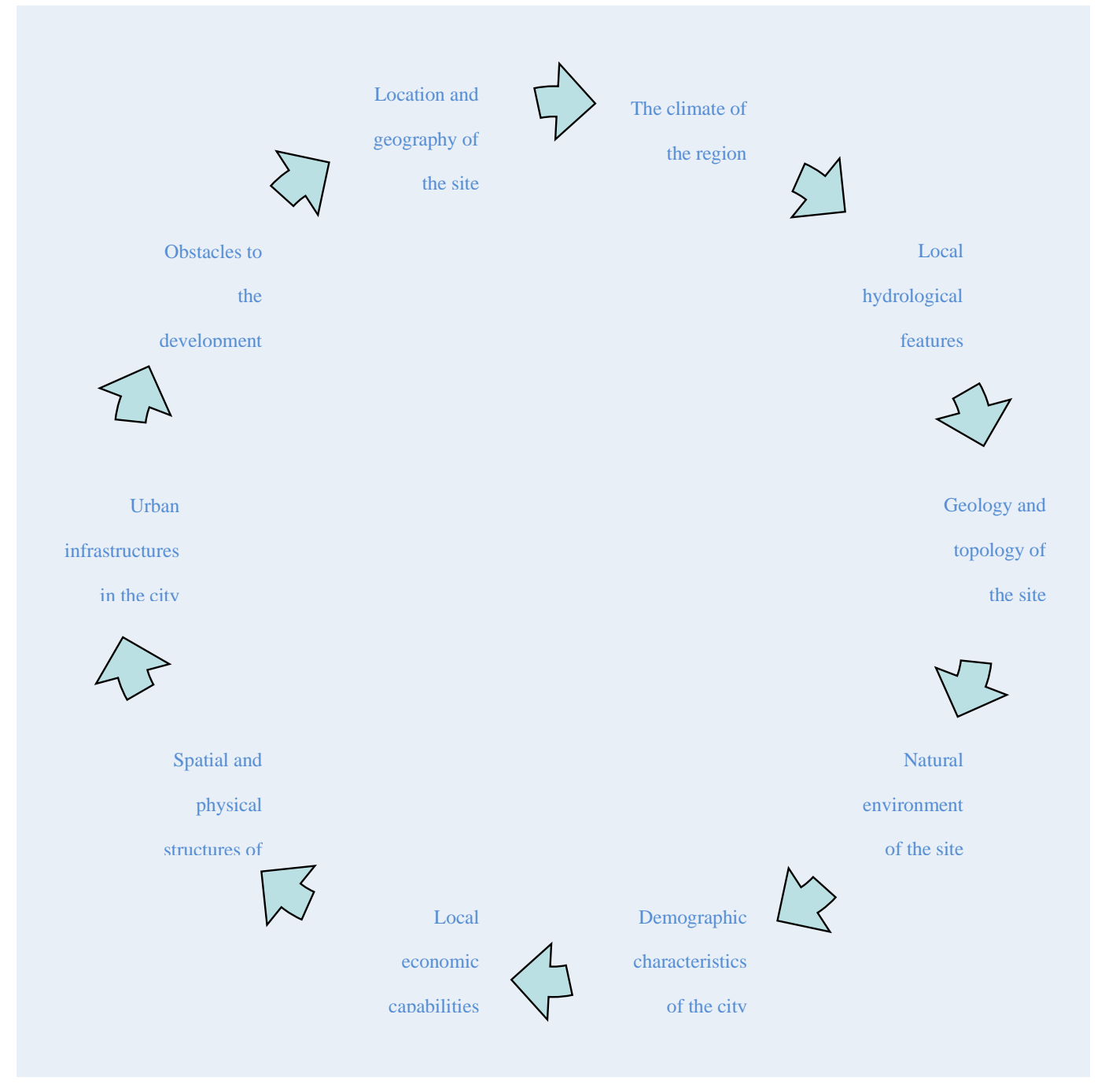

Figure 1 Variables affecting the location of tourism complexes (source: The result from the author's workshop experiences).

We will consider the variables presented in Figure 1 when designing the tourism complex location.

\subsection{Design of Tourism Complexes}

\subsubsection{The Process of Spatial Planning and Design of a Tourism Complex}

The building process of a tourism complex includes the following steps:

Firstly, introducing a representative team from the tourism industry to the urban strategic planning group. The representative helps the urban land use and outlines its policies and needs. The area and the location needed for the tourism industry will be defined in the master map of 
the city. The representatives will introduce types of tourism activities according to their regional potential and characteristics. The next step is deciding the location and land area for a tourism complex based on the theories and methods. We consider the possible tourist activities, the planners and entrepreneurs provide a table, including the location, tourism complex area, and geometric shape of the land allotted for spatial distribution. This table is a physical table of the tourism complex site. We then prepare a residential land-use map from the physical table. According to the land-use map, the architects and civil engineers design the architectural and structural maps of the required projects in the tourism complex building. These results are known as an album of maps. Finally, we set a timetable and implementation plan to build the tourism complex with detailed projects. The album of maps helps planners in constructing the operations. The following chart shows the step-by-step process (Figure 2):

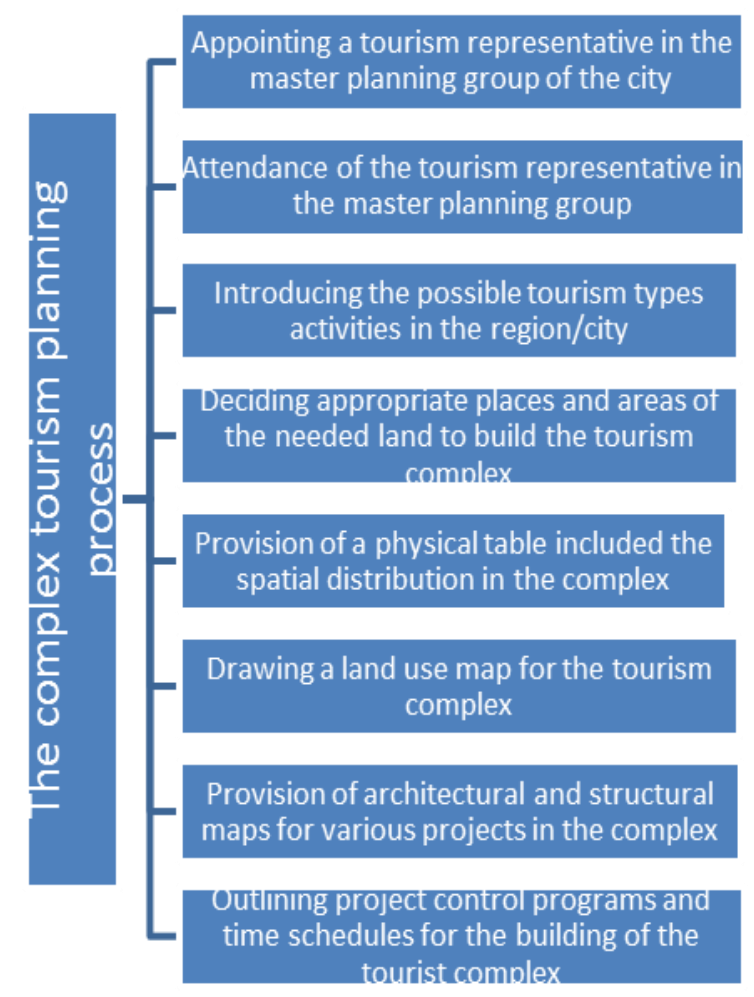

Figure 2 The flow chart for planning and constructing the tourism complex (Source: The result of the author's workshop experiences).

\subsubsection{Design of the Tourism Complexes Requires Policies}

It is necessary to study the tourism industry from two perspectives during the planning and construction of a tourism complex. It includes the perspective of the tourist and the hosts [36]. Here, the discussion involves the host's perspective. Philanthropy and altruism are the most important policies for a country competent to plan, design, and build a tourism complex and provide services for tourists. Good thinking, morally speaking, and worthy manners communities help encourage tourist arrivals. Cities require natural resources and the environment, animals, and people. Native people in the destination may be interested in inviting tourists. There are no possibilities where a community with hungry and worried people progresses in the tourism industry. Incompetent destinations cannot attract tourists to benefit economically. One cannot 
have a chaotic and dangerous transportation system and invite tourists. A disproportionate and ugly location does not attract tourists. It is impossible to beautify only a limited urban neighborhood and ask tourists to stay there. One cannot expect tourists to travel and spend money without the pertinent services. Thus, the first idea for planning tourism complexes should be humane, sustainable, with fair regional and urban strategic thinking.

\subsubsection{Planning an Attractive Tourism Complex}

A tourism complex will offer a good destination and services. Nasr studied the internal and external impacts on Egypt's tourism industry. He concluded that a good complex fulfills all the requirements of the customers [37]. The first crucial step in tourism development is planning and designing. People visiting the tourism complex are tourists from worldwide. Theoretical studies and experiences show that factors like hospitable people, good location, the attractive appearance of the surroundings, adequate regional and urban infrastructures, and good landscape influence the success of tourism complexes. It also includes quick and pleasant services, cleanliness, good food, and drink.

\subsubsection{The Most Significant Variable in the Design of Tourism Complexes:}

Table 2 introduces and considers some necessary factors while building a tourism complex. It shows the crucial variables with their indicators in the design of a tourism complex.

Table 2 Considerable Variables while designing an attractive tourism complex.

\begin{tabular}{|c|c|c|c|}
\hline Line & $\begin{array}{l}\text { Main variable } \\
\text { group }\end{array}$ & Indicators & References \\
\hline 1 & $\begin{array}{l}\text { Physical Status of } \\
\text { Buildings }\end{array}$ & $\begin{array}{l}\text { Structural strength and tolerance } \\
\text { Standard sizes, comfortable rooms, corridors, } \\
\text { and services } \\
\text { Architectural charm and beauty of the building } \\
\text { Heating and cooling facilities }\end{array}$ & $\begin{array}{l}{[3,19,23-26,} \\
29,36]\end{array}$ \\
\hline 2 & Infrastructures & $\begin{array}{l}\text { Quality of medical and health services } \\
\text { Quality access to bus, taxi, train, and aircraft } \\
\text { Quality of electronic communications services } \\
\text { Quality of the water and sewage networks }\end{array}$ & $\begin{array}{l}{\left[\begin{array}{l}14,23,24, \\
26,36,38]\end{array}\right.}\end{array}$ \\
\hline 3 & Landscape & $\begin{array}{l}\text { Rich ecosystem } \\
\text { Abundant natural resources } \\
\text { Attractive natural environment } \\
\text { Clean environment } \\
\text { The right of tourists to visit nature-protected } \\
\text { areas }\end{array}$ & $\begin{array}{l}{[24,25,32,} \\
36,38]\end{array}$ \\
\hline 4 & Management & $\begin{array}{l}\text { Expert and competent management of the } \\
\text { complex } \\
\text { Training programs to introduce guests to the } \\
\text { place }\end{array}$ & $\begin{array}{l}{\left[\begin{array}{ll}12, & 14, \\
24-27]\end{array}\right.}\end{array}$ \\
\hline
\end{tabular}




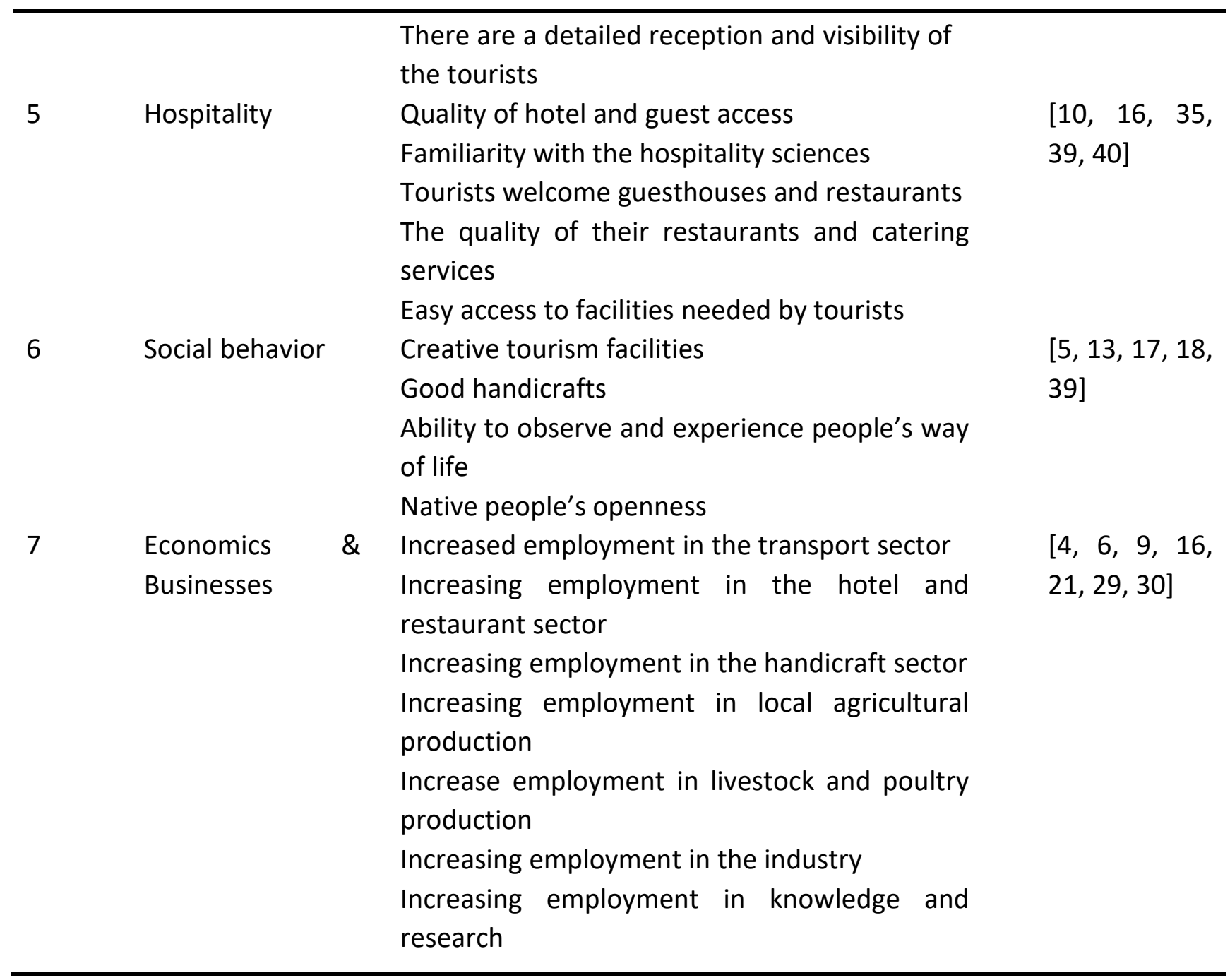

Source: Derived from the author's theoretical studies, field studies, and experiences.

Tables 1 and 2 show that the variables are abstracted from the theoretical studies, scholars' ideas, and our workshop experiences. Scholars commonly include tourism planning development in the process of regional/municipal master planning progresses for tourism industries and regional development.

\section{Methodology and Case Studies}

We see the application of locating theories, strategic planning lessons, land-use policies, and some design methods to build a seaside tourism complex in Chabahar. Experiences from workshops in strategic urban planning and designing with the theoretical advice from international scholars assist the case study.

\subsection{Where is Chabahar?}

Chabahar Port is on the southeastern edge of Iran along the Oman Sea and runs $122 \mathrm{~km}$ of the blue border along the Oman Sea and the Indian Ocean. It is 7 meters above sea level and has diverse natural and environmental attractions, pristine and beautiful ecotourism, and Geoeconomic privileges. We can see that in Figure 3. Chabahar is a destination for many Iranian and 
global travelers. The population of Chabahar is 106,739 people. The global attention on Chabahar, the Chabahar-Milak transit corridor, and its railroad are factors that encourage its tourism. Chabahar has hospitable people interested in business and working with the world, especially the neighboring countries. Its city infrastructure and region will improve Chabahar's capabilities. Thus, the allocation of land for constructing a tourism complex during its master plan is necessary.

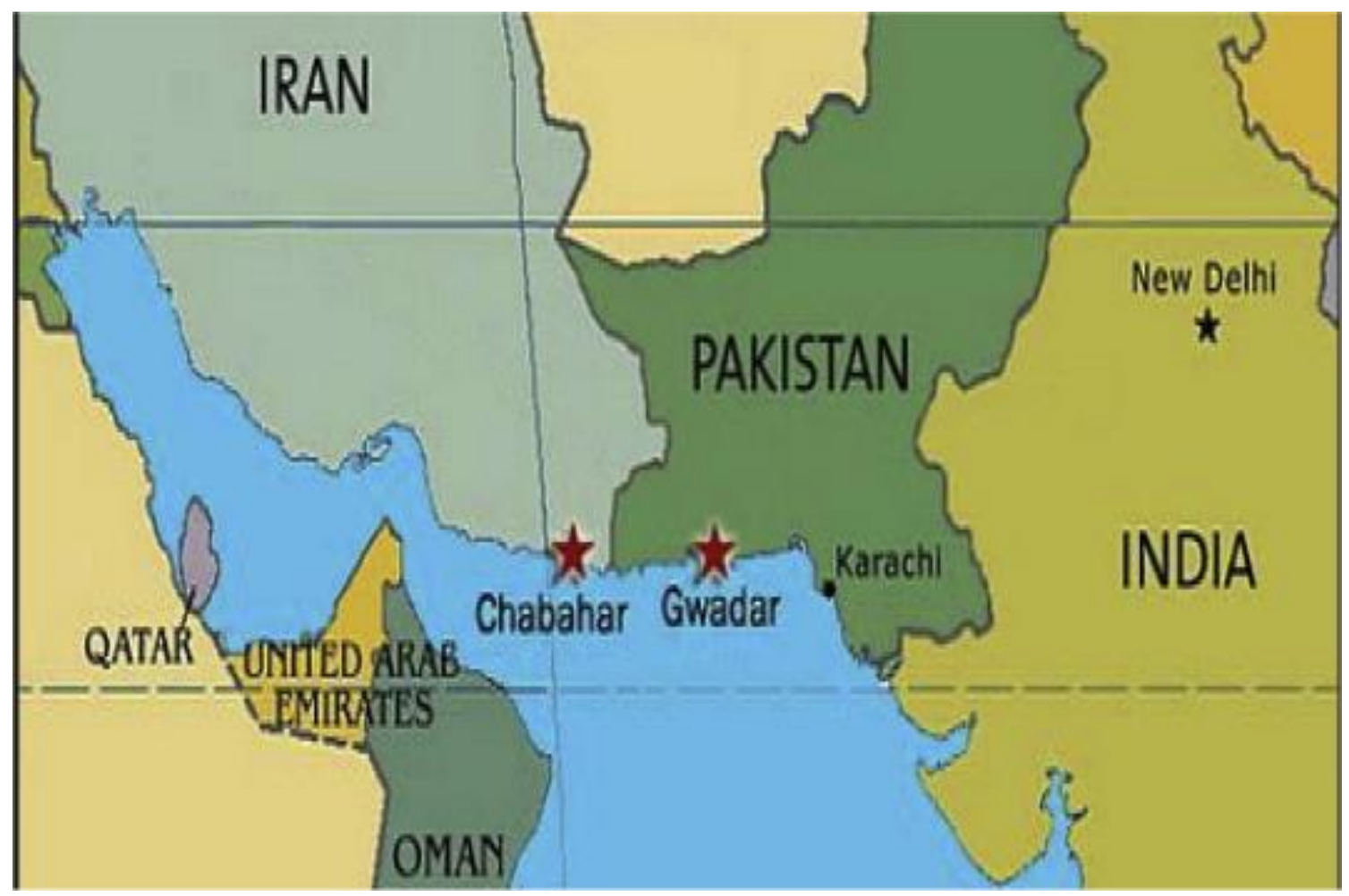

Figure 3 The situation of the Chabahar port in the region.

\subsection{The Location of Chabahar's Tourism Complex}

On the Oman Seashore, opposite to its desert, hills, and sea views that attract throngs of tourists, Chabahar's seaside tourism complex planning and designing helped fulfill tourist requirements.

Table 2 shows the locating theories and indicators outlined that determine the location of the tourism complex. Since Chabahar can plan for usual tourist activities, it needs more land. For the tourism industry, it occupies 2400 hectares of land in the outskirts of Chabahar in the vicinity of Ramin village and Lipar Lake. Figure 4 exhibits the place of the tourism complex in Chabahar. 


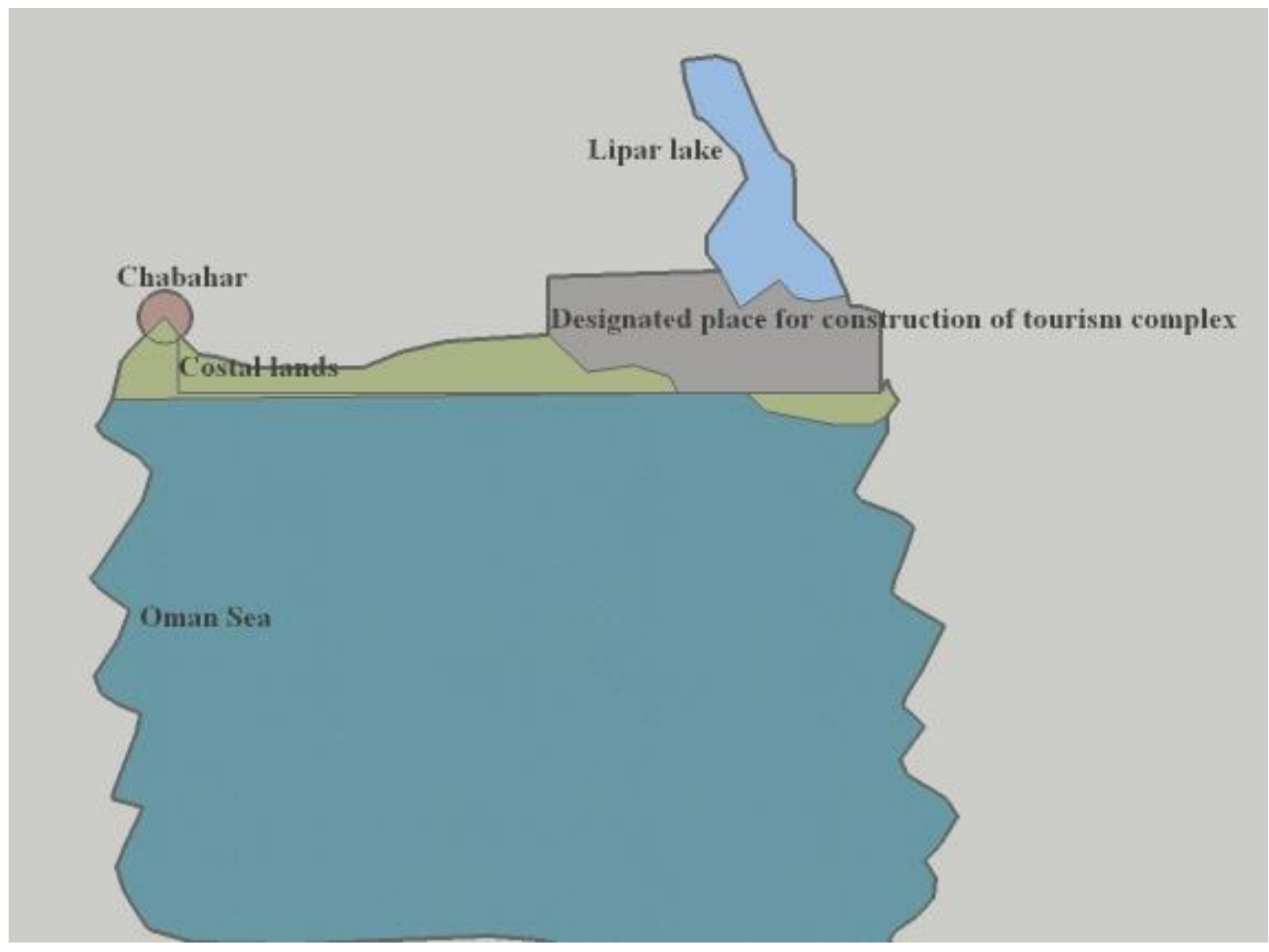

Figure 4 The location of the seaside tourism complex in Chabahar (source: Design by the author).

Figure 4, showing the designated place for the tourism complex, is gray. The tourism complex uses a problem-oriented strategy to develop regional socioeconomics. As Iranian officials say, Chabahar municipality considers tourism as an industry. They suggested that the tourism industry representative will be included in the urban master plan team. They need to consider tourism in the early stages of the municipal master plan. Thus, the city structure and its transportation network system should be modernized. The tourism complex of Chabahar includes the following spaces: management, camping, hotels, homes, economic activities, hospitality, education, health, sport, streets, greens, and infrastructure.

\subsection{Land-Use Policies in the Tourism Complex of Chabahar}

suggested the physical table showing the spatial distribution in the site to follow the land-use policies and allocate the required area. The table uses knowledge about the place and various types of tourism in Chabahar. The theories will help turn the region into a sustainable and prospective one. It will attract more tourists by connecting the tourism complex to its surrounding world with the necessary infrastructures. It needs a network of modern and inviting streets. It requires adequate land to accommodate modern transport stations, halls, and terminals. The tourism complex of Chabahar must allocate lands for various special functions like villas, catering, hotels, sports, education, commerce, workshops, green spaces, and infrastructure. The tourism 
complex of Chabahar considers the crucial strategic factors related to sustainable development. The seaside tourism complex in Chabahar includes several tourists. There are feasible activities linked to tourism like leisure, business, culture, food, nature, history, ecology, creativity, family, science and education, water, and sports in Chabahar. Table 3 exhibits the spatial distribution of land-use policies in the tourism complex of Chabahar.

Table 3 Land-use policy for various uses in a tourism complex.

\begin{tabular}{|c|c|c|c|}
\hline Category of use & Activities & Percent & Area/ha \\
\hline \multirow[t]{3}{*}{ Management } & 24-hour reception & $1 \%$ & 24 \\
\hline & 24-hour security & & \\
\hline & 24-hour doctor & & \\
\hline \multirow[t]{2}{*}{ Camping } & Location of travel tent & $4 \%$ & 96 \\
\hline & Car parking for passengers & & \\
\hline \multirow[t]{2}{*}{ Residential } & 500 rum hotel & $22 \%$ & 528 \\
\hline & 200 villas & & \\
\hline \multirow[t]{5}{*}{ Economic } & Gift shop & $10 \%$ & 240 \\
\hline & Businesses & & \\
\hline & Handicrafts exhibition & & \\
\hline & Seafood exhibition & & \\
\hline & Agricultural exhibition & & \\
\hline \multirow[t]{11}{*}{ Hospitality } & Restaurants & $10 \%$ & 240 \\
\hline & Cinema & & \\
\hline & Event planning & & \\
\hline & Local visits services & & \\
\hline & Ferry services & & \\
\hline & Foreign exchange & & \\
\hline & Guest fridge & & \\
\hline & Guest laundry & & \\
\hline & Ice machine & & \\
\hline & Luggage storage & & \\
\hline & Internet & & \\
\hline \multirow[t]{5}{*}{ Education } & Short courses in local geography & $2 \%$ & 48 \\
\hline & Short courses in Baluchi language & & \\
\hline & Short courses in indigenous culture & & \\
\hline & Short courses in Native Art & & \\
\hline & Short courses in the local music & & \\
\hline \multirow[t]{4}{*}{ Medical } & Doctors office & $5 \%$ & 120 \\
\hline & Dentist's office & & \\
\hline & Medical and nursing services & & \\
\hline & Psychological services & & \\
\hline \multirow[t]{3}{*}{ Sport } & Halls for sport competitions & $10 \%$ & 240 \\
\hline & Beach volleyball & & \\
\hline & Tennis hall & & \\
\hline
\end{tabular}




\begin{tabular}{llll}
\hline & Golf & \\
& Swimming pool & & \\
& Riding camel & $25 \%$ & 600 \\
Streets and squares & Streets & & \\
& Plazas & & \\
Intersections & $8 \%$ & 192 \\
Green & Beach Park & \\
Infrastructures & Children's play park & & \\
& Transport infrastructure & $3 \%$ & \\
& Telecommunications infrastructure & & \\
& Water supply and distribution & & \\
& Sewage network & & \\
Total used lands & Electricity infrastructure & 2,400 \\
\hline
\end{tabular}

Reference: The author's workshop activities.

The table's right column shows the area for each category of land use. It includes undertaking the above projects at the tourism complex site with a land-use map. See the same in Figure 5. Based on the information in the table, the land use map defines the tourism complex.

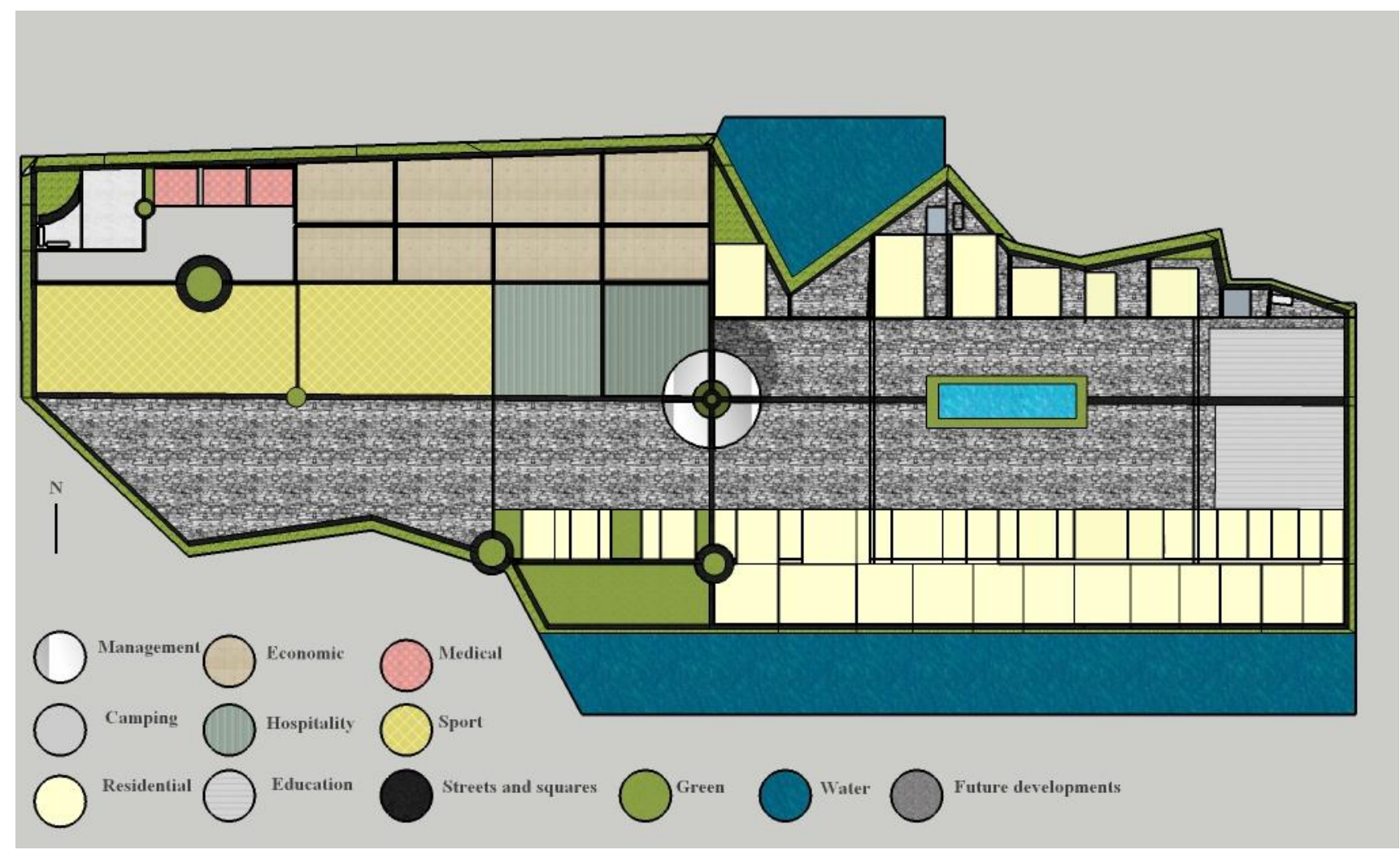

Figure 5 Land-use map of the seaside tourism complex in Chabahar (source: Design by the author).

The investors in this unique project can choose among the proposed lots. The central tourism complex will be accessible by foot, bicycle, or automobile. It creates an almost vehicle-free zone. 
The modern and inviting network of sidewalks serves as a vibrant lifeline for the tourism complex, connecting all its attractions and services.

\subsection{The Design Methods Applied in the Chabahar Seaside Tourism Complex}

They used a centralized design method to separate the seaside tourism complex physically and visually. The central tourism complex captivates the tourists and provides administrative and functional services. Figure 5 shows the elements of the tourism complex site with approximately 2,400 hectares of land. This centralization with the lifestyle and needs of the local people develops it physically and economically. This method of design also makes the site beautiful. This site considers business, hotels, and exhibitions in this center. This method creates a strong and efficient central area. The buildings are symmetric, beautiful, attractive, and climate-friendly. Figure 6 shows a 3D map of the tourism complex.

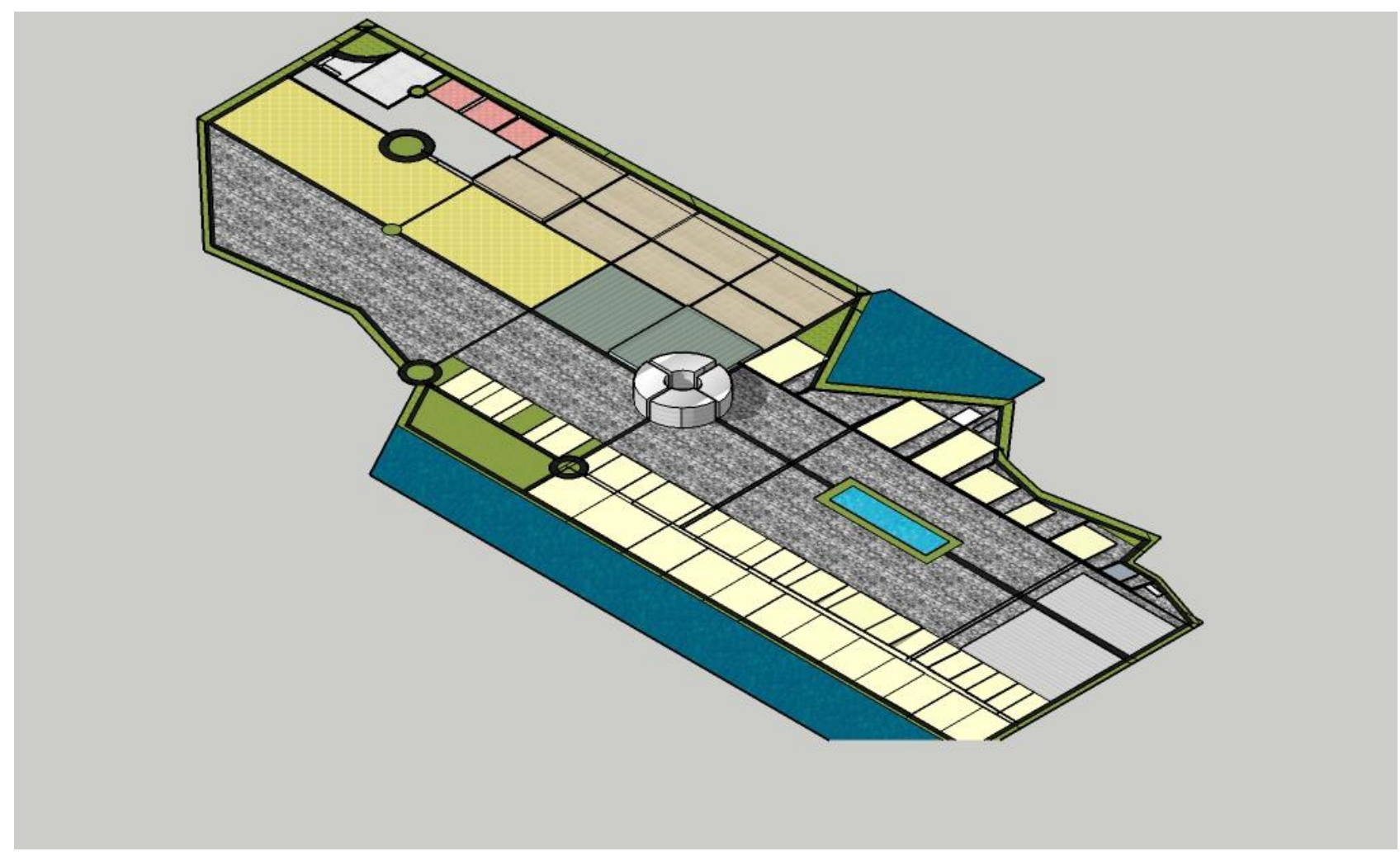

Figure 6 An Isometric 3-dimensional map of the seaside tourism complex in Chabahar (source: Design by the author).

Ratios help emphasize the center while designing the various parts of the tourism complex. Emphasizing the importance of proportional heights of the buildings in the other parts of the tourism complex is a design style. In the residential, economic, hospitality, sport, and camping parts, buildings are shorter than the central part to maintain height proportion. Colors, water, and trees help make the tourism complex more attractive. They emphasize expanding green spaces and suitable trees on the map. They used the balancing method in various parts of the tourism complex. This method uses the visual weight of the villas to promote social justice. It also helps create unity between tourists and the local people who reside in the 96-hectare camping area. Regional economics will improve by combining the interests and the cultural, scientific, social, and 
economic programs. The proposed rhythmic design technology will help connect multiple parts of the tourism complex. In this design model, They placed all streets, plazas, and parks in residential, economic, medical, education, and sport parts with beautiful trees, pedestrian benches at convenient distances, light, and water. It is vital to communicate between components of the tourism complex. For example, Figure 7 exhibits the maritime transport infrastructure designed in this tourism complex.

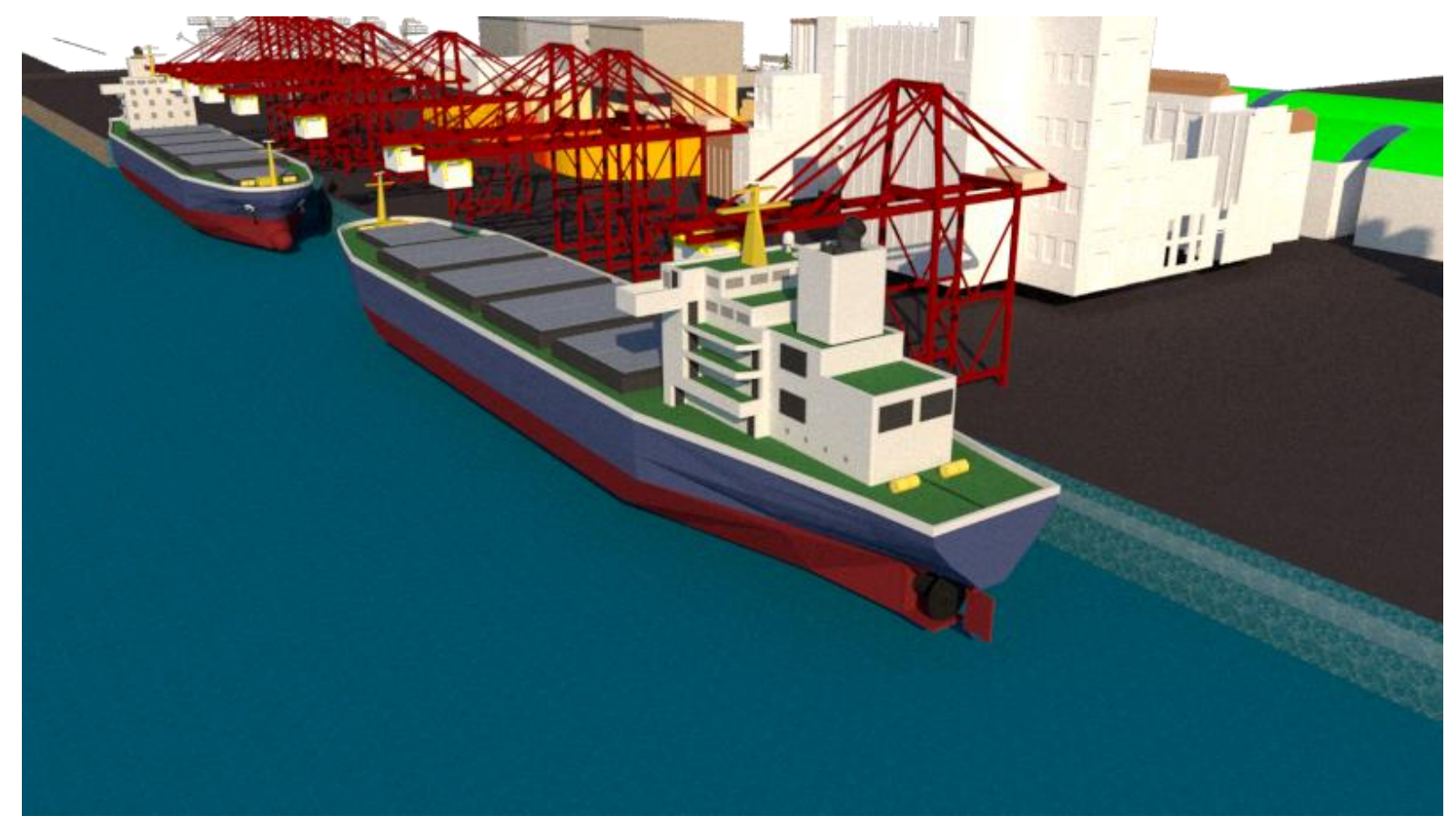

Figure 7 The 3D view of the Maritime transport infrastructure in the tourism complex of Chabahar (source: Design by the author).

These actions lead to a beautiful and efficient unity throughout the skeleton of the tourism complex. The preparation of an album of architectural, structural, and executive maps comes after it. Finally, there are outlining schedules for implementation and control of projects to build the tourism complex.

\section{Discussion}

The literature review is necessary for tourism development with several types of tourism. Its strategic planning, defining the location of tourism complexes, and methods with the case studies, can be analyzed from literature. They follow appropriate location theories and models for Chabahar. Scholars recommended places with adequate infrastructure, an attractive natural environment, and improved services for building a tourism complex. It helps satisfy tourists and develop the tourism industry through host communities and travel destinations. Thus, several countries want more share in this global industry. Therefore, each region with tourist attractions plans to build tourism complexes according to their cultural, social, climatic, natural, and economic characteristics. This planning also helps prepare a comprehensive map of the city. Figure 1 introduces eleven variables affecting the site selection for every tourism complex. The variables are based on the analysis of requirements and possibilities in the place. Although the variables are 
general and differ in different countries, they assist planners with a rational location of tourism complexes everywhere.

They determined the location and required land area of the seaside tourism complex in Chabahar through strategic planning. As the theory suggests, the planning, design, and construction process of the tourism complex followed a systematic flowchart. The planning uses step-by-step activities. It introduces the representatives of the tourism industry to the municipal master plan group. It even helps define the types of regional tourism and their requirements. The other includes selecting a suitable site for the complex and preparing a physical table of its spatial distribution. It is followed by preparing a map of the land use and an album of architectural and executive maps for the complex. Finally, the designing of the tourism complex in Chabahar happens.

A hypothesis estimates that tourism development requirements in the municipal master plan improve tourism industries and regional development simultaneously. We found observations and experiences that the construction of tourism complexes can be economically successful and increase the quality of life in tourist host communities [38].

Tourism complexes boost the tourism industry. Experiences prove that as the desirability of tourism complex planning increases, so does the economic growth and quality of life of the local people [39]. Tourism is an outcome of development where local communities want to improve their quality of life [40].

The place chosen to build a tourist complex on the Chabahar coast is according to its strategic location. Figures 3 and 4 show the advantages of this region which lead to the successful tourism complex. Table 3 is a physical table of the spatial distribution and a land-use table. It shows the required elements of the tourism complex. Chabahar complex has adequate infrastructure, streets and passages, squares, green space, and central management. It has camping, residential areas, economic, catering, educational areas, and medical, sports, and services. Several activities are performed, and the required land area is determined. The total required land for the site is 2,400 hectares.

The design methods applied a centralized model for building an impressive and functional center. The symmetric model with ratios contributed to maintaining desired site harmony. The design method helps emphasize the importance of proportional heights of the buildings in the complex. Colors, water, and trees also make the design more attractive. The design methods promote social justice by connecting tourists and the local people in the camping area with its 96hectare land. A proposed rhythmic design model connects the tourism complex with necessary accessibility. The design model connects all streets, plazas, parks, homes, economic centers, medical buildings, education offices, and sport parts.

According to studies on the significance of the tourism industry in developing economies, there are efforts to design an attractive and optimal tourist complex. The seaside tourism complex will also simultaneously develop tourism and economic prosperity of the Chabahar region.

\section{Conclusions}

This study reviewed the importance of developing tourism complexes for optimal tourism hospitality and regional development. It enhanced the skills in developing tourism complexes during the urban master plan. We also considered the tourism industry requirements in the 
process of urban/regional development. Thus, the study analyzed strategic policies for tourism development to write a guideline for its case studies. We also considered the methods for finding suitable places (locations) to build tourism complexes. The practical procedures of this study revealed the relationship between providing optimal services for tourists and the socioeconomic and physical development of destinations.

This paper applied centralized and symmetric design models to achieve optimal results and social justice with the step-by-step tourism development process. The research analysis proved the possibility of economic growth through optimal planning and design of the tourism complexes. All agents of the tourism industry and regional/urban development everywhere can use the research outcome to improve tourism and increase economic prosperity. This article can also be a reference for educational courses in tourism sciences, the construction of tourism complexes, and regional development.

\section{Author Contributions}

The author did all the research work of this study.

\section{Competing Interests}

The author has declared that no competing interests exist.

\section{References}

1. Smith VL. Hosts and guests: The anthropology of tourism. Philadelphia: University of Pennsylvania Press; 2012.

2. Horita Y. Urban development and tourism in Japanese cities. Tour Plan Dev. 2018; 15: 26-39.

3. James KJ. Tourism, land and landscape in Ireland: The commodification of culture. New York: Routledge; 2014.

4. Holloway JC, Humphreys C. The business of tourism. Thousand Oaks: SAGE Publications Limited; 2019.

5. Wiktor-Mach D. What role for culture in the age of sustainable development? UNESCO's advocacy in the 2030 Agenda negotiations. Int J Cult Policy. 2020; 26: 312-327.

6. Kumar TV, Dahiya B. Smart economy in smart cities. In: Smart economy in smart cities. Singapore: Springer; 2016. pp.3-76.

7. Coccossis $\mathrm{H}$, Mexa $\mathrm{A}$. The challenge of tourism carrying capacity assessment: Theory and practice. New York: Routledge; 2017.

8. UNWTO. Statistics [Internet]. Madrid: UNWTO; 2017. Available from: http://cf.cdn.unwto.org/sites/all/files/factsheet june2015.pdf.

9. WTTC. Travel and tourism economic impact. London: World Travel \& Tourism Council; 2014.

10. Kuščer K, Eichelberger S, Peters M. Tourism organizations' responses to the COVID-19 pandemic: An investigation of the lockdown period. Curr Issues Tour. 2021: 1-14. doi: 10.1080/13683500.2021.1928010.

11. Shah C, Chowdhury A, Gupta V. Impact of COVID-19 on tourism and hospitality students' perceptions of career opportunities and future prospects in India. J Teach Travel Tour. 2021: 1-21. doi: 10.1080/15313220.2021.1924921. 
12. Raun J, Ahas R, Tiru M. Measuring tourism destinations using mobile tracking data. Tour Manag. 2016: 57: 202-212.

13. Nunkoo R. Governance and sustainable tourism: What is the role of trust, power and social capital? J Dest Mark Manage. 2017; 6: 277-285.

14. Fodness D. The problematic nature of sustainable tourism: Some implications for planners and managers. Curr Issues Tour. 2017; 20: 1671-1683.

15. Bramwell B, Lane B. What drives research on sustainable tourism? J Sustain Tour. 2015; 23: 13.

16. Hall CM. Intervening in academic interventions: Framing social marketing's potential for successful sustainable tourism behavioural change. J Sustain Tour. 2016; 24: 350-375.

17. Clarke J, Bowen D. Familiar tourists, their behaviours and place attachments: An empirical framework. Tour Recreat Res. 2018; 43: 417-431.

18. Sharpley R. Tourism, tourists and society. London: Routledge; 2018.

19. Shahraki AA. Transportation planning and design in Chabahar. Zahedan: University of Sistan and Baluchistan; 2018.

20. Pred A. City-systems in advanced economies: Past growth, present processes and future development options. New York: Routledge; 2017.

21. Hjalager AM, Gesseneck MJ. Capacity-, system-and mission-oriented innovation policies in tourism-Characteristics, measurement and prospects. J Policy Res Tour Leis Events. 2020; 12: 197-216.

22. Kahila-Tani M, Kytta M, Geertman S. Does mapping improve public participation? Exploring the pros and cons of using public participation GIS in urban planning practices. Landsc Urban Plan. 2019; 186: 45-55.

23. Asmelash AG, Kumar S. Assessing progress of tourism sustainability: Developing and validating sustainability indicators. Tour Manag. 2019; 71: 67-83.

24. Lew AA. Tourism planning and place making: Place-making or placemaking? Tour Geogr. 2017; 19: 448-466.

25. Dwyer L, Tomljenović R, Čorak S. Evolution of destination planning and strategy: The rise of tourism in croatia. London: Palgrave Macmillan; 2017.

26. Ivanov D, Tsipoulanidis A, Schönberger J. Global supply chain and operations management. A decision-oriented introduction to the creation of value. Berlin: Springer; 2019.

27. Shahraki AA. Regional development assessment: Reflections of the problem-oriented urban planning. Sustain Cities Soc. 2017; 35: 224-231.

28. Richards HA. Transportation costs and plant location: A review of principal theories. Transp J. 1962; 2: 19-24.

29. Marchionatti R. Economic theory in the twentieth century, an intellectual history-volume I. London: Palgrave Macmillan; 2020.

30. Bryson JM. Strategic planning for public and nonprofit organizations: A guide to strengthening and sustaining organizational achievement. Hoboken: John Wiley \& Sons; 2018.

31. Coelho MS, Carlos PP, Pinto VD, Meireles A, Negreiros D, Morellato LP, et al. Connection between tree functional traits and environmental parameters in an archipelago of montane forests surrounded by rupestrian grasslands. Flora. 2018; 238: 51-59.

32. Lalicic L, Önder I. Residents' involvement in urban tourism planning: Opportunities from a smart city perspective. Sustainability. 2018; 10: 1852. 
33. Shahraki AA. Sustainable regional development through knowledge networks: Review of case studies. Front Archit Res. 2019; 8: 471-482.

34. Higgins B. Regional development theories and their application. New York: Routledge; 1997.

35. Tournois $L$, Rollero $C$. What determines residents' commitment to a post-communist city? A moderated mediation analysis. J Prod Brand Manag. 2019; 29: 52-68.

36. Bigné $E$, Decrop A. Paradoxes of postmodern tourists and innovation in tourism marketing. In: The future of tourism. Berlin: Springer; 2018. pp.131-154.

37. Nasr N. Influence of the internal and external environment on the sustainability of business in Egypt' tourism industry. IJHTH. 2018; 12: 160-180.

38. Liburd JJ, Benckendorff P, Carlsen J. Tourism and quality-of-life: How does tourism measure up? In: Handbook of tourism and quality-of-life research. Dordrecht: Springer; 2011. pp.105132.

39. Westcott M, Bird G, Briscoe P, Freeman R, Glazer K, Henry K, et al. Introduction to tourism and hospitality in BC. North Vancouver: Capilano University; 2012.

40. Boukas N, Ziakas V. Tourism policy and residents' well-being in Cyprus: Opportunities and challenges for developing an inside-out destination management approach. J Dest Mark Manage. 2016; 5: 44-54.

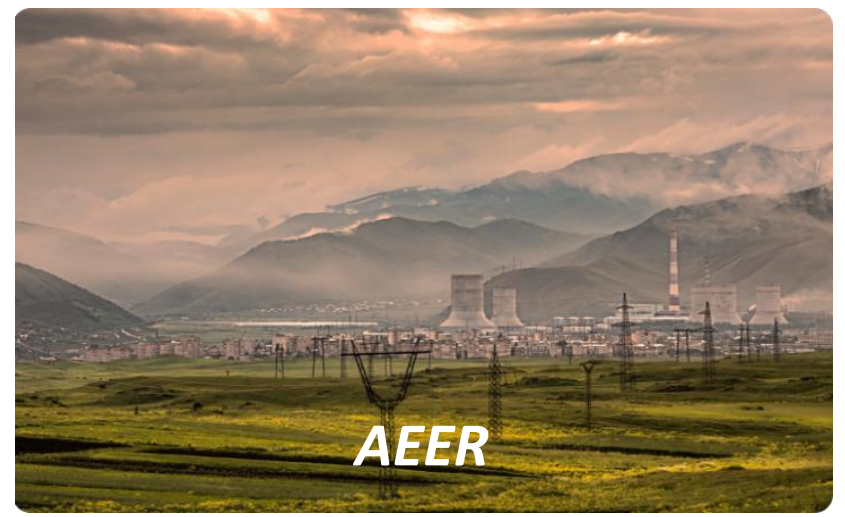

Enjoy AEER by:

1. Submitting a manuscript

2. Joining in volunteer reviewer bank

3. Joining Editorial Board

4. Guest editing a special issue

For more details, please visit:

http://www.lidsen.com/journals/aeer 